\title{
STUDY OF PHYSICOCHEMICAL PROPERTIES AND ZOOPLANKTON DIVERSITY OF OGUTA LAKE IN OGUTA LOCAL GOVERNMENT AREA OF IMO STATE
}

\author{
Anyanwu J.C., Onyedilefu, U.G. \\ Department of Environmental Management,
} Federal University of Technology, Owerri, Nigeria.

\begin{abstract}
The study aimed at determining the physicochemical parameters of Oguta Lake and to assess the composition and abundance of zooplankton assemblage of the lake in order to determine the relationship between the physicochemical parameters and zooplankton abundance in the lake. Three sampling stations were established, and standard method was used in the collection and analysis of the water samples for physicochemical parameters and zooplankton identification and enumeration. The study was delineated into three sampling locations within the lake. They are: Njaba (Station A or SA); Orashi (Station B or SB) and Ossemotor (Station C or SC). Mean concentrations of the physicochemical parameters vary across the stations. The sampling was done in the morning before 8:00 am on weekly basis between the months of August to October, 2018. Pour-through method was used to collect the samples. An average of 43 species of zooplankton from the different stations were identified and ---- individuals enumerated in this study. The dominant class in Njaba station was Protozoa with 10 individuals, followed by Rotifera with 7 individuals, Cladocera with 3 individuals was next, and others recorded 1 or 2 individuals. The dominant class in Orashi Station was Cladocera with 13 individuals, followed by copepoda and rotifera which both had 12 individuals. In Ossemottor Station, the class Cladocera dominated with 12 individuals, followed by the class Rotifera with 11 individuals while class Copepoda was next with 3 individuals. The individuals of class Rotifera, Protozoa and Cladocera were observed in all 3 sampling stations. This showed that zooplankton of class rotifer, protozoa and cladocera were more adapted to the environmental conditions in Oguta Lake.Statistical analysis demonstrated a significant correlation between the occurrence of some zooplankton species and some physicochemical parameters. As a result, it was concluded that physicochemical properties might significantly impact the zooplankton species in Oguta Lake and as such it was recommended that there should be legislation to discourage the discharge of wastes into the lake as the nutrient rich wastes can cause eutrophication which in the long run will affect the zooplankton composition of the lake.
\end{abstract}

Keywords: Composition, Eutrophication, Lake, Physicochemical, Zooplankton,
Nwobu E.A.

Department of Quantity Surveying, Nnamdi Azikiwe University, Awka, Anambra State, Nigeria

\section{INTRODUCTION}

The pivotal role of zooplankton in aquatic food web and their grazing activities in phytoplankton populations have been recognized. They function as intermediaries between fish and lower trophic levels. Their importance as food to juvenile and adult fish is well known (Ogbeigbu, 2001). Zooplankton generally occupy a central role in the aquatic food web as many of them feed largely on algae and bacteria and in turn fall prey to numerous invertebrates and fish predators. This factors coupled with their high sensitivity to environmental factors, has drawn the attention of several biologists focusing on zooplankton occurrence, composition, distribution and significant role in pollution studies (Ogbeibu and Obanor, 2002). The efforts of hydrologists to preserve a healthy aquatic environment are strengthened through monitoring of the physicochemical condition of the water. These parameters when not monitored cause a subtle but extensive damage and distortion at the primary, secondary and tertiary production in the aquatic ecosystem. Pollutants from domestic and industrial wastes, heavy metals, organic wastes among many others into the aquatic ecosystem constitute public hazards (Arimoro and Osakwe, 2006).

In recent years, there has been increasing concern about the rate at which inland waters are polluted through run offs into streams and lakes, as in oguta lake, sometimes leading to eutrophication, this affect the specific composition of zooplanktons and variation in physico- chemical parameters as well as changing the qualities of these water bodies. (Chapman and Romberg, 2008). Changes may have happened over a period of time in Oguta lake because of how the neighbouring communities resort to use of lake for agriculture, recreation, livestock and human consumption due to insufficiency of pipe borne water. These activities of the surrounding communities of Oguta lake may affect the physicochemical parameter and zooplankton composition in relation to season as well as the quality of the water. Zooplankton play an important role in our oceans, on biogeochemical cycling and providing food source for commercially important fish larvae. However difficulties in correctly indentifying zooplankton hinder our understanding of their roles in marine ecosystem functioning and can prevent detection of long term changes in community structure. The aim of this study into assess the composition and abundance of zooplankton assemblage of Oguta Lake and to determine the physicochemical parameters of the lake. 

METHODOLOGY

\section{A. Study Area}

The study was conducted at Oguta Lake. The lake is located on latitudes $5^{0} 41^{\prime}$ and $5^{\circ} 44^{\prime}$ north and longitude $6^{0} 45^{\prime}$ and $6^{0} 50^{\prime}$ 'East, within the equatorial rainforests belts in Imo State. The Oguta blue lake is the largest natural lake in Imo State and in Nigeria as a whole, it is said to have originated from a natural depression. It is the largest hydrological features in Imo State and services several adjoining communities along its boundaries. Four rivers are associated with the lake. The Njaba and Awbana Rivers flow into the lake; the Orashi River flows into the lake at its south eastern end and the Utu River which is the fourth, flows through the lake only during the rainy season (Nwadiaro, I989). It has been reported that the surface areas of the lake during the wet and dry seasons are 1.8 and $2.5 \mathrm{~km}$, respectively, while the maximum depth is about $8.0 \mathrm{~m}$ (Nwadiaro, 1989). The lake is located in a region within the equatorial rain forest belt with an average annual rainfall of $3,100 \mathrm{~mm}$. Most of the rain forest has been replaced by oil palm plantations especially around the lake. Oguta lake has a high diversity of zooplankton community. The lake is of vital economic importance to the inhabitants of the area serving the function of water supply, fishing and sand mining. The common fish species are identified by their local names and include Ebi(Mud fish), Atuma (Catfish), Egu(Tilapia), Oporoma, Ifuru and Ofu (Omin,1983). It has been observed that a total of 2,403 full-time fishermen and 154 part-time fishermen operate in the lake.

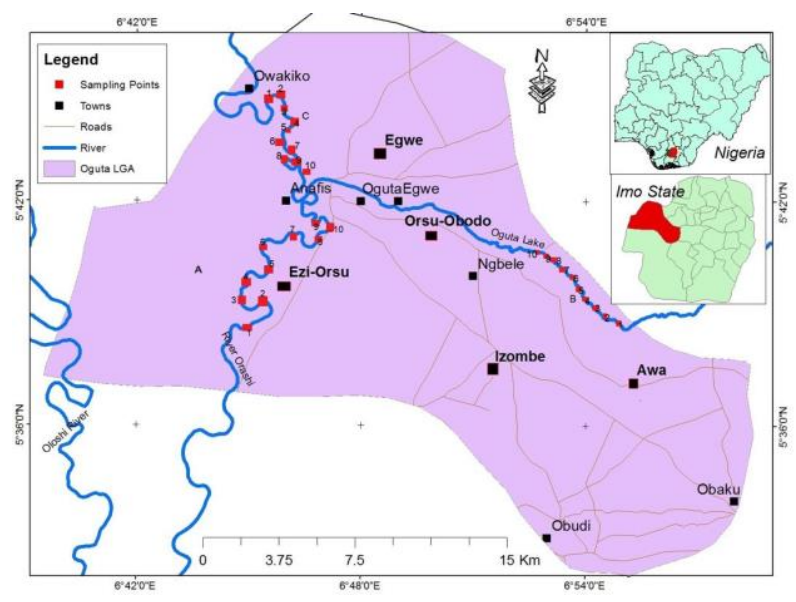

Fig.1. Map of Study area showing Oguta Lake

The climate is tropical high forest with two distinct seasons, a dry season which lasts from October to March, and the rainy season which lasts from April to September (Nnaji, 2011). The wind direction in Oguta area is mostly south-west, North-west and west with the south-west wind being the strongest (Anyanwu and Oueke, 2003). The area is located within the Equatorial rain forest belt of Nigeria, with an average annual rainfall of $3,100 \mathrm{~mm}$. Most of the rainfall is recorded between the month of May and October (NRCRI, 2012) although most of the rainforest had been replaced by oil palm plantations especially around the lake. The temperature is generally high with an average of $27^{\circ} \mathrm{C}$. The hottest months are February and March when the temperature rises to between $33^{\circ} \mathrm{C}$ and $35^{\circ} \mathrm{C}^{\prime}$.

The vegetation cover includes shrubs and economical tree such as oil palm, Indian bamboo, avocado pear,
African breadfruit, oil bean and raffia palms. Due to the tile relatively steep shore line and significant water current aquatic macrophytes, especially the floating and rooted submerged vegetation are sparse.

\section{B. Study Locations}

The study was delineated into three sampling locations within the lake. They are: Njaba (Station A or SA); Orashi (Station B or SB) and Ossemotor (Station C or SC). Station A (Njaba or Njaba River) is a major tributary of Oguta lake. It has a flow rate of about $700 \mathrm{~m}^{3} /$ hour, with a substratum characterized by zooplanktons, plants and sand. Station B consists mainly of zooplanktons, invertebrates, sand and organic materials.Fishing activities are noticeable here. The substratum of Station C consists of zooplanktons, phytoplanktons, plants, invertebrates, sand, pebbles and other substances.

The criteria for the selection of the sampling stations were based on preliminary surveys of the lake and other factors including accessibility, discharge, average depth, security and the different anthropogenic activities taking place within the lake and the surrounding area.

\section{Sample collection}

Water Samples and Zooplanktons were collected at different stations. The zooplanktonswere collected with the use ofplankton nets of size $50 \mu \mathrm{m}$ which was used to drag through horizontally and vertically on the lake. The sampling was done in the morning before 8:00 am on weekly basis between the months of August to October, 2018. Pour-through method was used to collect the samples. A 10-liter graduated bucked was used to collect water at a depth of about $30 \mathrm{~cm}$ below the water surface and then poured into a plankton net of mesh size $50 \mu \mathrm{m}$, this was done 10 times to make a total of 100 litres of filtered water. The collected zooplankton were then carefully transferred into properly labeled storage containers, $4 \%$ of formalin was added which served as a preservative for zooplankton. The samples were taken to the laboratory for further analysis (i.e. for viewing and identification).

The water samples were collected with sterile containers, properly labeled, stored in a refrigerator and taken to the laboratory within 72 hours of collection for analysis of physicochemical parameters of the lake.

\section{Sample identification}

Identification of the zooplanktons was done with the use of a compound microscope. A dissecting microscope was used for sorting and counting the number of species. After they were taken to the laboratory, each preserved plankton sample was poured into a graduated centrifuge tube and centrifuged using a 'Gallen Kamp- Medico' model (90) centrifuge. This was allowed to settle and the supernatant decanted. After decanting the concentrated plankton was analyzed. The Specimens were mounted on glass slides and examined at 25100X magnification. A pipette was used to place the concentrated plankton on a glass slide with a cover slip and then viewed under a compound. The planktons were then identified (qualitative analysis) and counted (quantitative analysis) using standard identification keys and taxonomic guide (Pennak, 1979; Jeje and Fernando, 1986). The general body shape, the color (Opaque or translucent), the relative 
length of appendages (e.g. antennae, legs) and setae (hair-like processes) were features used in identification of the zooplankton species. The above processes were repeated five times, in orderto determine the abundance and diversity of zooplankton at the three stations.

\section{E. Statistical Analysis}

The estimation of species abundance and diversity of zooplankton was done using Margalef's Diversity
Index (D), Shannon-Wiener Diversity Index (HI) and Simpson's Index (D) methods (Simpson, 1949). Simpson index (d) was used to evaluate species richness. The Shannon-Weiner index $(\mathrm{H})$ and evenness index (E) of Shannon and Wiener (1963) were used to evaluate species diversity. Correlation analysis was employed to determine the relationship between the physicochemical parameters and the zooplankton abundance of the lake.

III. RESULT

Table 1. Diversity indices of zooplankton species of Oguta Lake, Nigeria

\begin{tabular}{|c|c|c|c|c|c|c|c|}
\hline Stations & \begin{tabular}{|l}
$\begin{array}{l}\text { Number } \\
\text { of } \\
\text { species }\end{array}$ \\
(S)
\end{tabular} & $\begin{array}{l}\text { Number of } \\
\text { individuals }\end{array}$ & \begin{tabular}{|c|} 
Dominance \\
(D)
\end{tabular} & $\begin{array}{l}\text { Simpson's } \\
\text { index (1 - } \\
\text { D) }\end{array}$ & $\begin{array}{l}\text { Equitabilit } \\
\text { index } \\
(\mathrm{J})\end{array}$ & $\begin{array}{l}\text { Shannon- } \\
\text { Weiner } \\
\text { index } \\
\text { (H') }\end{array}$ & $\begin{array}{l}\text { Heterogeneity } \\
\text { Index }\end{array}$ \\
\hline $\begin{array}{l}\text { NJABA (SA) } \\
\text { (AUGUST) }\end{array}$ & 14 & 91 & 0.07934 & 0.9207 & 0.9794 & 2.585 & 0.0793 \\
\hline $\begin{array}{l}\text { NJABA(SA) } \\
\text { (SEPTEMBER) }\end{array}$ & 13 & 94 & 0.08128 & 0.9187 & 0.9886 & 2.536 & 0.0813 \\
\hline $\begin{array}{l}\text { NJABA (SA) } \\
\text { (OCTOBER) }\end{array}$ & 18 & 139 & 0.05978 & 0.9402 & 0.9871 & 2.853 & 0.0598 \\
\hline $\begin{array}{l}\text { ORASHI (SB) } \\
\text { (AUGUST) }\end{array}$ & 15 & 96 & 0.07661 & 0.9234 & 0.9735 & 2.636 & 0.0766 \\
\hline $\begin{array}{l}\text { ORASHI(SB) } \\
\text { (SEPTEMBER) }\end{array}$ & 15 & 110 & 0.07025 & 0.9298 & 0.9898 & 2.681 & 0.0702 \\
\hline $\begin{array}{l}\text { ORASHI (SB) } \\
\text { (OCTOBER) }\end{array}$ & 17 & 145 & 0.06321 & 0.9368 & 0.9877 & 2.798 & 0.0632 \\
\hline $\begin{array}{l}\text { OSSEMOTO } \\
\text { (SC) } \\
\text { (AUGUST) }\end{array}$ & 12 & 54 & 0.1056 & 0.8944 & 0.9534 & 2.369 & 0.1056 \\
\hline $\begin{array}{l}\text { OSSEMOTO } \\
\text { (SC) } \\
\text { (SEPTEMBER) }\end{array}$ & 11 & 75 & 0.09831 & 0.9017 & 0.9802 & 2.350 & 0.0983 \\
\hline $\begin{array}{l}\text { OSSEMOTO } \\
\text { (SC) } \\
\text { (OCTOBER) }\end{array}$ & 13 & 83 & 0.08637 & 0.9136 & 0.9751 & 2.501 & 0.0864 \\
\hline
\end{tabular}

SA = Station A, SB = Station B, SC = Station C

Table 1 shows the monthly zooplankton diversity index of Oguta Lake at the different stations for the period studied. The monthly trend of ShannonWiener index for the lake at Njaba Station can be depicted as October is higher than November is higher than Augustand November is higher than August. The maximum (2.853) values of zooplankton species diversity was recorded in October whereas the minimum (2.536) was observed for September. The concentration of dominance was in the order September is higher than August is higher than October and August is higher than October. The species dominance ranged from 0.05978 (October) to 0.08128 (September). The trend for Simpson's index is depicted as October is higher than September is higher than August and September is higher than August. The maximum value (0.9402) was recorded in October while the minimum value $(0.9187)$ was recorded in September. The equitability or evenness index was highest (0.9886) in September and lowest (0.9794) in August. Species heterogeneity was in the order September is higher than August is higher than October and August is higher than October 
The monthly trend of Shannon-Wiener index for the lake at Orashi Station can be depicted as October is higher than September is higher than Augustand September is higher than August. The maximum values (2.798) of zooplankton species diversity was recorded in October whereas the minimum (2.636) was observed for August. The concentration of dominance was in the order August is higher than September is higher than October and September is higher than October.

The species dominance ranged from 0.06321 (October) to 0.07661(August). The trend for Simpson's index is depicted as October is higher than September is higher than August and September is higher than August. The maximum value (0.9368) was recorded in October while the minimum value (0.9234) was recorded in August. The equitability or evenness index was highest (0.9898) in September and lowest (0.0632) in August. Species heterogeneity was in the order August is higher than September is higher than October and September is higher than October.

The monthly trend of Shannon-Wiener index for the lake at Ossemotor Station can be depicted as October is higher than August is higher than Septemberand August is higher than September. The maximum values (2.501) of zooplankton species diversity was recorded in October whereas the minimum (2.350) was observed for September. The concentration of dominance was in the order August is higher than September is higher than October and September is higher than October.

Table 2..Physicochemical parameters of Oguta Lake.

\begin{tabular}{|c|c|c|c|c|}
\hline Parameters & Station A & Station B & Station C & Mean sample \\
\hline Temperature $\left({ }^{\circ} \mathrm{C}\right)$ & 32.1 & 31.3 & 31.5 & 31.6 \\
\hline $\mathrm{pH}$ & 5.57 & 5.89 & 5.36 & 5.61 \\
\hline Conductivity(us/cm) & 128 & 82 & 59 & 89.67 \\
\hline Turbidity (NTU) & 21 & 19 & 32 & 24 \\
\hline TSS (mg/l) & 14.0 & 11.6 & 18.2 & 14.6 \\
\hline Colour & 89 & 62 & 130 & 93.67 \\
\hline Appearance & Clear & Clear & Clear & Clear \\
\hline Nitrate $(\mathrm{mg} / \mathrm{l})$ & 0.8 & 0.9 & 0.7 & 0.8 \\
\hline Phosphate (mg/l) & 0.04 & 0.06 & 0.42 & 0.17 \\
\hline Sulphate (mg/l) & 1.8 & 1.2 & 2.4 & 1.8 \\
\hline Potassium (mg/l) & 2.1 & 2.5 & 1.8 & 2.13 \\
\hline
\end{tabular}

The species dominance ranged from 0.08637(October) to 0.1056(August). The trend for Simpson's index is depicted as October is higher than September is higher than August and September is higher than August. The maximum value (0.9136) was recorded in October while the minimum value (0.8944) was recorded in August. The equitability or evenness index was highest (0.9802) in September and lowest (0.9534) in August. Species heterogeneity was in the order August is higher than September is higher than October and September is higher than October. In all the stations, there were more individual species of zooplankton in the month of October than the other months.

The trend of Shannon-Wiener index for stations on Oguta Lake (Table 4.1) is depicted as SA is higher than SB is higher than SC and SB is higher than SC. The maximum value (2.853) of zooplankton species diversity was recorded in SA whereas the minimum (2.350) was recorded in SC. The concentration of dominance was in the order $\mathrm{SC}$ is higher than $\mathrm{SA}$ is higher than SB and SA is higher than SB. The Simpson's index ranged from 0.8944 (SC) to 0.9402 (SA). The Equitability or evenness index was highest in SB (0.9898) and lowest (0.9534) in SC. Species heterogeneity was in the order SC is higher than SA is higher than SB and SA is higher than SB.

SB had the highest number of individual species of zooplankton while SC had the lowest. 
International Journal of Engineering Applied Sciences and Technology, 2020

Vol. 4, Issue 10, ISSN No. 2455-2143, Pages 328-336

Published Online February 2020 in IJEAST (http://www.ijeast.com)

Lead $(\mathrm{mg} / \mathrm{l})$

Manganese (mg/l)

0.34

Unpleasant

Odour
0.19

Unpleasant

0.25

0.3

0.56

0.08

Different environmental factors play important roles in the development and abundance of zooplankton (Suresh et al., 2011). It is on this basis that the analysis of the physicochemical parameters of Oguta Lake was carried out.Table 4.2 shows the result of the physicochemical analysis of water samples from Oguta Lake. There were wide variations in the physicochemical properties of the water. The variations in the physicochemical properties of the water brought about changes in the composition and abundance of aquatic organisms in the lake. Temperature ranged from $31.3{ }^{\circ} \mathrm{C}$ (Station B) to $32.1^{\circ} \mathrm{C}$ (Station C). The mean temperature of the lake was $31.6{ }^{\circ} \mathrm{C}$. Station B had the highest $\mathrm{pH}$ value of 5.89 while Station $\mathrm{C}$ had the lowest value of 5.36. This indicates that Station $\mathrm{C}$ was more acidic than other stations. The mean $\mathrm{pH}$ of the Lake was 5.61. Conductivity, turbidity, total dissolved Solids, colour, nitrate, phosphate, lead, manganese, iron, and cadmium varied from $59-128$ us $/ \mathrm{cm}, 19-32$ NTU, $11.6-18.2 \mathrm{mg} / \mathrm{l}, 62-130,0.7-0.9 \mathrm{mg} / \mathrm{l}, 0.04-$ $0.42 \mathrm{mg} / \mathrm{l}, 0.19-0.25 \mathrm{mg} / \mathrm{l}, 0.1-0.3 \mathrm{mg} / \mathrm{l}, 0.34-0.56$ $\mathrm{mg} / \mathrm{l}, 0.02-0.08 \mathrm{mg} / \mathrm{l}, 1.2-2.4 \mathrm{mg} / \mathrm{l}, 1.8-2.5 \mathrm{mg} / \mathrm{l}$, with mean values of $89.67 \mathrm{us} / \mathrm{cm}, 24 \mathrm{NTU}, 14.6$ $\mathrm{mg} / \mathrm{l}, 93.6,0.8 \mathrm{mg} / \mathrm{l}, 0.17 \mathrm{mg} / \mathrm{l}, 1.8 \mathrm{mg} / \mathrm{l}, 2.13 \mathrm{mg} / \mathrm{l}$, $0.23 \mathrm{mg} / \mathrm{l}, 0.23 \mathrm{mg} / \mathrm{l}, 0.46 \mathrm{mg} / \mathrm{l}$, and $0.05 \mathrm{mg} / \mathrm{l}$ respectively. From the result it can be seen that station $\mathrm{C}$ was mostly impacted by the physicochemical parameters compared to other stations.

\section{DISCUSSION}

Species abundance of zooplanktons varied widely between the different stations studied. In comparison to the diversity of species in studies carried out on other major lakes in Southern Nigeria, the richness of zooplankton in Oguta Lake is quite low. One would have expected a much higher diversity of zooplankton species in the lake because of its location in the tropical rainforest region. This is because high rainfall and vegetation tend to influence the qualitative and quantitative levels of zooplankton species in a water body. In the studies carried out by Arora and Naresh (2003), and Egborge (1981) in different water bodies, it was reported that high vegetation provided anchorage to the resting eggs and larva stage of zooplankton. The low richness of zooplankton species in Oguta Lake in comparison to other lakes might be attributed to the acidification of the lake and various human activities and environmental factors within the different stations of the lake where the study was carried out. Arora and Naresh (2003) reported that such differences could also be attributed to geographical factors as well as trophic state of the water body. The average number of zooplankton species in the lake for the months of study, was 43 which is lower than the 65,78 and 65 species recorded for Adada River, Asejire Lake and Bonny River respectively, by Egborge in 1981 and Jeje and Fernando in 1986. The number of zooplankton species recorded for Oguta Lake in this current research was also lower than the number recorded (65) in the same lake by Jeje and Fernando in 1986 which is an indication of a decline in diversity of zooplankton species in the lake over time. However, the number recorded was higher than the zooplankton species observed in some lakes in the northern part of the country such as 18 species in Tiga Lake and 13 species in Kainji Lake from works carried out by Abdullahi (1989) and Ovie etal.(2000) respectively. Not all the identified species were present in all the stations. Stations A and B had higher number of species than Station C. The species with the highest number of individuals include Diffuga Species (Protozoa), Euchlanis iyra (Rotifera), Alonella exigua (Cladocera), Ploesoma hudsoni (Rotifera),Cyclopoid Species (Adult), Synchaeta pectinata (Rotifera), Alonella Excisa (Cladocera), Protozoa (Ciliophora), Cyclopoid Species (Adult) (Copepoda), Pelectpod Larva, Alonella exigua (Cladocera) and Alona rectangula (Cladocera). There are changes in the abundance of zooplankton in the different stations. For instance, not all the identified species were found in all the stations studied. Some were completely absent in some stations while others were found in two or three of the stations studied (Appendix A). These changes in species composition can be as a result of variations in the physicochemical properties of the lake. Ahmad et al. (2011) reported that the presence of some species of plankton fauna is limited by factors such as dissolved oxygen, $\mathrm{pH}$, temperature, salinity, or other physical and/or chemical properties. The result of the physicochemical parameters in Table 4.2 revealed that the $\mathrm{pH}$ of Stations A and $\mathrm{C}$ were lower than that of Station B. The lower acidity of Station B may be responsible for this station having higher species diversity than the other stations. This agrees with the findings of Bernarz et al. and Musapha $(2002,2009)$ who reported that alkaline conditions favour the growth and abundance of zooplankton. Station $\mathrm{C}$ had the lowest $\mathrm{pH}$ value and the lowest number of species. Thus the low number of species can be attributed to the high acidity of the water. This is also in line with the findings by Dehui, Yamada and Ikeda $(1995,1999)$, and by that of Ivanova and Kazantseva (2006), were they reported that low $\mathrm{pH}$ causes reduced zooplankton abundance, as well as decreased biodiversity and the loss of some species.

The temperature of the lake in Station B was equally lower than other stations. The higher temperature values of Station A and C can equally be attributed to 
the low species composition in these stations. This is in agreement with the findings of Hall and Burns (2001) that water temperature impacts the growth and development of organisms and can influence their mortality. The implication is that where there is high mortality as a result of increase in water temperature, the number of individual species as well as the diversity of species will be on the decline. This is also in line with the assertion by Andrulewicz et al. and Tunowski $(2008,2009)$ that different species show varied tolerances to increase or reductions in temperature ranges, and that sensitive individuals are eliminated by them.

Similarly, the turbidity was lowest in Station B, which had the highest diversity of species, and highest in Station C, which had the lowest species diversity. Turbidity decreases the penetration of light in water. Without the presence of light producers will not be available and this will affect the distribution and diversity of aquatic fauna. Phytoplankton and zooplankton population are usually limited by availability of light. While the phytoplankton which are the producers are directly impacted, the zooplankton which depends on the producers are impacted indirectly. It has also been reported by Andrulewicz et al. (2008) that light also exerts an indirect impact on other physical factors such as temperature and water colour. From the result of the physicochemical analysis (Table 4.2), it can be seen that Station B was more transparent than other stations as indicated by the colour of the water. Thus the high turbidity in Station $\mathrm{C}$ increased its colour which is an indication of poor penetration of light, resulting in low species presence in that station compared to other sampling stations.

The result also revealed variation in the nitrate, phosphate, potassium and sulphate content of the Lake at the various stations. These variations in these chemicals can be said to be partly responsible for the differences in the species present in the different stations. It is expected that when nutrient is available and in abundance, aquatic species will increase in population. The high nitrate, phosphate and potassium contents of Station $B$ can be said to be partly responsible for the high species abundance there compared to other stations. Wang et al. $(2007,2008)$ reported that the availability of nutrients, significantly impacts the structure and abundance of zooplankton. It has also been reported by (Ojaveer $e t$ al., 2010) that changes in nutrients are directly responsible for some species disappearing and others occurring. The findings is also in line with Perumal et al (2009) who further stated that changes in nutrients can also have an indirect impact on zooplankton abundance by causing scarcity of food. Gonzalez et al. (2011) further reported that when nutrient status are modest, large herbivorous forms such as Calanoida copepods and large water fleas, tend to dominate whereas in fecund waters, small detritivore forms and predatory organisms such as Cyclopoda copepods, small water fleas and rotifers dominate. Station $\mathrm{C}$ had the highest level of heavy metals (lead, manganese, iron and cadmium) compared to other stations. The high heavy metal contents in Station $\mathrm{C}$ may have contributed to the decline in the number and diversity of species in that station, this is because high toxicity of chemicals in water are detrimental to the development and survival of aquatic organisms. Lead particularly is toxic to aquatic fauna. Some of these chemicals even in low concentrations can cause variation in the distribution of zooplankton species. Sensitive species are more vulnerable to the presence of these chemicals. Some sensitive species may also be forced to migrate to other locations. The microfauna can also accumulate these chemicals, posing health risks to organisms higher in the food chain. Station B had the lowest level of these chemicals in water and also the highest number of zooplankton species in the lake.

The result of the correlation analysis revealed both positive and negative correlations of diverse magnitude. The result established high, moderate and low correlations between the parameters on one hand and between the parameters and the number of zooplankton species on the other hand. There was a very strong negative association between $\mathrm{pH}$, conductivity, potassium, nitrate and sulphate and the number of zooplankton species in the three sampling stations. There is also a high association between lead, manganese and iron and the zooplankton species in some of the sampling stations. Perfect positive correlation existed between $\mathrm{Mn}$ and lead $(+1)$ and between zooplankton species and sulphate $(+1)$, while perfect negative correlation existed between sulphate and nitrate $(-1)$ and between zooplankton species and nitrate $(-1)$. The correlations were statistically significant between some of the parameters and the zooplankton population in the sampling stations. The correlations were significant at 0.05 level for colour and $\mathrm{pH}(-0.97191)$, nitrate and $\mathrm{pH}$ (0.9929), sulphate and $\mathrm{pH}(-0.9929)$ potassium and $\mathrm{pH}$ (0.99932), zooplankton and turbidity (0.98974), zooplankton and nitrate (0.97207), zooplankton and colour (0.99301), zooplankton and pH (-0.9929). The other parameters did not show significant correlations. The strong positive and negative correlation of most of the values is an indication of a strong association between the physicochemical parameters and the zooplankton composition of the lake. The implication is that the physicochemical properties might significantly impact the zooplankton species in Oguta Lake.

TABLE 3.3. CORRELATION MATRIX OF PHYSICOCHEMICAL PARAMETERS AND ZOOPLANKTON SPECIES IN OGUTA LAKE

\begin{tabular}{|c|c|c|c|c|c|c|}
\hline \multirow{2}{*}{\multicolumn{2}{|c|}{$\begin{array}{c}\text { TEMP } \\
\text { PHOSHATE }\end{array}$}} & $\mathrm{CON}$ & TURBI & ITY & \multirow{3}{*}{$\begin{array}{l}\text { TSS COLOUR } \\
\text { MANGANESE }\end{array}$} & \multirow{3}{*}{$\begin{array}{l}\text { NITRATE } \\
\text { IRON }\end{array}$} \\
\hline & & SULPHATE & POTASSIUM & LEAD & & \\
\hline CADMIUM & NSPA & NSPB & NSPC & & & \\
\hline
\end{tabular}

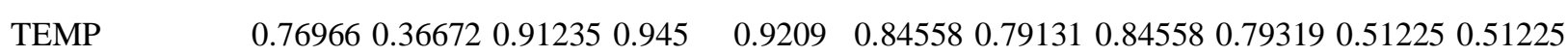
$0.421170 .966620 .94213 * \quad 0.821090 .94558$

$\mathrm{pH} \quad-0.35398$ 


\title{
International Journal of Engineering Applied Sciences and Technology, 2020 \\ Vol. 4, Issue 10, ISSN No. 2455-2143, Pages 328-336
}

Published Online February 2020 in IJEAST (http://www.ijeast.com)

\author{
$\begin{array}{lllllllllllll}\text { CONDUCT } & 0.83863 & 0.21258 & 0.54563 & 0.68828 & 0.71239 & 0.7877 & 0.42459 & 0.7877 & 0.84009 & 0.87896\end{array}$ \\ $\begin{array}{llllllll}0.87896 & 0.054454 & 0.66667 & 0.575410 .55437 & 0.68771\end{array}$
}
TURBIDITY $\quad-0.13725-0.87782-0.65465 \quad 0.142650 .166760 .242080 .121040 .242080 .294460 .57541$ $\begin{array}{llllll}0.57541 & 0.49118 & 0.12104 & 0.02978 & 0.091258 & 0.24208\end{array}$ $\begin{array}{llllllll}\text { TSS } & 0.08628 & -0.96231-0.470320 .975 & 0.024106 & 0.099425 & 0.26369 & 0.099425\end{array}$
COLOUR
$0.12393-0.97191^{*}$
$-0.436570 .965890 .99928$
0.075319
0.28779 0.075319
0.127710 .408650 .408650 .657930 .045719
0.136980 .258010 .075319
NITRATE $\quad-0.240190 .9929 * 0.32733-0.92857-0.98783-0.99301 \quad 0.363119 .0032 \mathrm{E}-06$

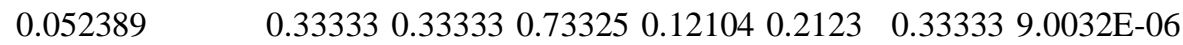

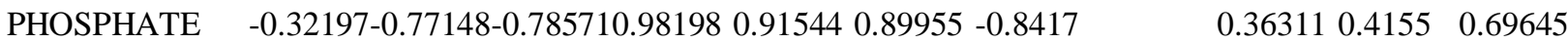
0.696450 .370140 .242080 .150820 .029780 .36311
SULPHATE $\quad 0.24019-0.9929 *-0.327330 .928570 .987830 .99301 * \quad-1 \quad 0.8417$

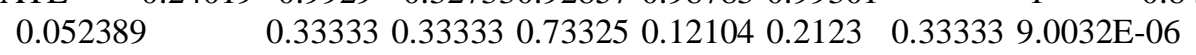

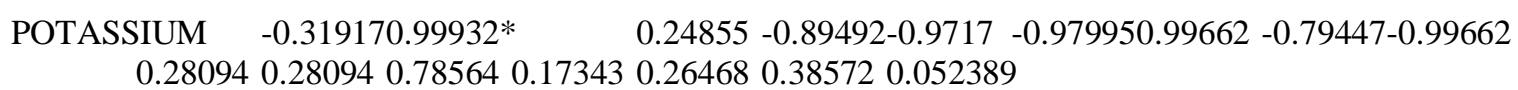

LEAD $\quad 0.69338-0.919360 .188980 .618590 .777710 .80095-0.866030 .458960 .86603-0.90419$ 9.0032E-06 0.933420 .454370 .545630 .666670 .33333
MANGANESE $0.69338-0.91936 * \quad 0.188980 .618590 .777710 .80095-0.866030 .458960 .86603-0.90419$ $1 \quad 0.933420 .454370 .545630 .96667 * \quad 0.33333$
IRON $\quad-0.78903-0.29528-0.996340 .716840 .543990 .51184-0.406860 .835690 .40686-0.33039-0.1044-0.1044$ $0.612210 .520950 .399920 .93325 *$

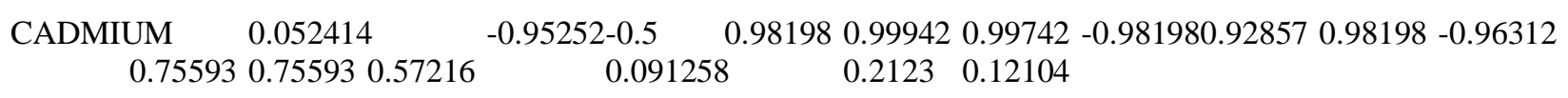

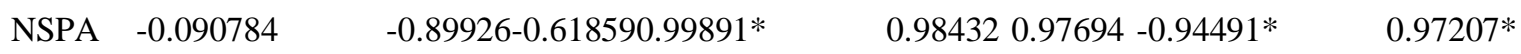

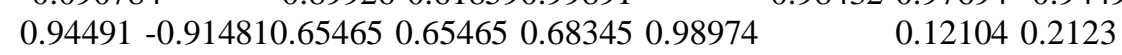

$\begin{array}{lllll}\text { NSPB } & -0.27735-0.80039-0.755930 .98974 * & 0.93326 & 0.91899-0.866030 .99891 * & 0.86603-0.82199\end{array}$ $\begin{array}{llllll}0.5 & 0.5 & 0.80909 & 0.94491 & 0.98198 & 0.33333\end{array}$

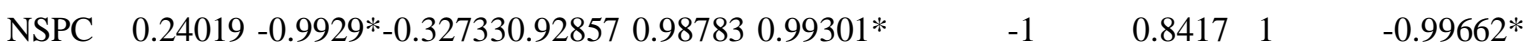
$\begin{array}{llllll}0.86603 & 0.86603 & 0.40686 & 0.98198 & 0.94491 & 0.86603\end{array}$

*Significant at 0.05 level

TEMP $=$ Temperature, CONDUCT $=$ Conductivity, NSPA $=$ Number of species in Sampling point A NSPB $=$ Number of species in Sampling point B, $\mathrm{NSPC}=$ Number of species in Sampling point $\mathrm{C}$.

The result of the correlation analysis (Table 3.3) revealed both positive and negative correlations of diverse magnitude. The result established high, moderate and low correlations between the parameters on one hand and between the parameters and the number of zooplankton species on the other hand. There was a very strong negative association between $\mathrm{pH}$, conductivity, potassium, nitrate and sulphate and the number of zooplankton species in the three sampling stations. There is also a high association between lead, manganese and iron and the zooplankton species in some of the sampling stations. Perfect positive correlation existed between $\mathrm{Mn}$ and lead $(+1)$ and between zooplankton species and sulphate $(+1)$, while perfect negative correlation existed between sulphate and nitrate (-1) and between zooplankton species and nitrate (-1). The correlations were statistically significant between some of the parameters and the zooplankton population in the sampling stations. The correlations were significant at 0.05 level for colour and $\mathrm{pH}(-0.97191)$, nitrate and $\mathrm{pH}$ (0.9929), sulphate and $\mathrm{pH}(-0.9929)$ potassium and $\mathrm{pH}$ (0.99932), zooplankton and turbidity (0.98974), zooplankton and nitrate (0.97207), zooplankton and colour (0.99301), zooplankton and $\mathrm{pH}(-0.9929)$. The other parameters did not show significant correlations. The strong positive and negative correlation of most of the values is an indication of a strong association between the physicochemical parameters and the zooplankton composition of the lake. The implication is that the physicochemical properties might significantly impact the zooplankton species in Oguta Lake.

\section{CONCLUSION}

Species abundance of zooplanktons varied widely between the different stations of Oguta Lake studied. In comparison to the diversity of species in studies carried out on other major lakes in Southern Nigeria, the richness of zooplankton in Oguta Lake was very low and this was attributed to the acidification of the lake and various human activities and environmental factors within the different stations of the lake where the study was carried out. The increasing rate of pollution of the lake affects the specific composition of zooplanktons and variation in physicochemical parameters of the water body and thus has caused significant change in the quality of the lake. These changes may have happened over a period of time in Oguta Lake because of how the neighboring communities resort to use of the lake for recreation, agriculture, livestock and human consumption due to 
absence or nonfunctional pipe borne water. The importance of Zooplankton in the aquatic ecosystem cannot be overemphasized, they are important in the biogeochemical cycling and in providing food source for commercially important fish larvae. An average of 45 species of zooplankton were identified in the months under study. Not all the identified species were present in all the stations. Stations A and B had higher number of species than Station C. The species with the highest number of individuals include Diffuga Species (Protozoa), Euchlanis iyra (Rotifera), Alonella exigua (Cladocera), Ploesoma hudsoni (Rotifera),Cyclopoid Species (Adult), Synchaeta pectinata (Rotifera), Alonella Excisa (Cladocera), Protozoa (Ciliophora), Cyclopoid Species (Adult) (Copepoda), Pelectpod Larva, Alonella exigua (Cladocera) and Alona rectangula (Cladocera). Some species were completely absent in some stations while others were found in two or three of the stations studied. These changes in species composition can be as a result of variations in the physicochemical properties of the lake. There were wide variations in the nitrate, phosphate, potassium and sulphate content of the Lake at the various stations. These variations in these chemicals can be said to be partly responsible for the differences in the species present in the different stations. It is expected that when nutrient is available and in abundance, aquatic species will increase in population. The high nitrate, phosphate and potassium contents of Station B was said to be partly responsible for the high species abundance there compared to other stations. These changes in nutrients are directly responsible for some species disappearing and others being present. The high heavy metal contents in Station C contributed to the decline in the number and diversity of species in that station, this is because high toxicity of chemicals in water are detrimental to the development and survival of aquatic organisms. Sensitive species are more vulnerable to the presence of these chemicals, particularly lead, even when present in low concentrations. This have in most cases resulted in sensitive species migrating to other locations. Station B had the lowest level of these chemicals in water and also the highest number of zooplankton species in the lake. This shows that there was an association between the chemicals and the zooplankton population in the lake.

\section{RECOMMENDATIONS}

Based on the above conclusion, the following recommendations are made:

i. There should be legislation to discourage the discharge of wastes into the lake as the nutrient rich wastes can cause eutrophication which in the long run will affect the zooplankton composition of the lake.

ii. Periodic monitoring of the Lake should be carried out so as to ensure that the concentration of chemicals in the water do not exceed the regulatory standards.

iii. There is need for sensitization and education of the indigenous populations that depend on the lake for their livelihood and as a source of water for drinking and domestic activities, on the need to reduce those activities that contribute to the pollution of the lake and adversely affect the zooplankton community.

iv. There is need for more extensive study on the distribution and composition of zooplankton species in Oguta Lake with a view to gaining more insight into the factors that control the distribution of the species.

\section{REFERENCES}

1. Abolude, I. S., Chia, A.M., Yahaya, A.S and Okafor, D.C. (2012). Phytoplankton Diversity and Abundance as a function of Water Quality the Fish Production: a case study of two Manmade Reservoir in Zaria Nigeria. Tropical Fresh Water Biology 21 (2): (pp.41-48).

2. Adakole, .J.A., Abolude, D.S. and Balarahe, M.L. (2008). Assessment of Water Quality of Man Made Lake in Zaria, Nigeria. Proceedings of Taal: The 12th World Lake Conference, (pp.1373-1382).

3. Araoye, P.A. (2008). Physical Factors and their Influence on Fish Species Composition in Asa Lake, Ilorin, Nigeria. International Journal of Typical Biology 57(1-2): (pp.167-175).

4. Ararimo, F. 0, and Osakwe, IL 1. (2006). The influence a sawmill wood wastes on the distribution and population of macroinvertebrates at Benin River, Niger Delta Area, Nigeria. Chemistry and Biodiversity, 3: (pp.578-592).

5. Atobatele, O.E. and Ugwumba, O.A (2008). Seasonal Variation in the Physicochemistryof a Small Tropical Reservoir (Aiba Reservoir, Iwo, Osun, Nigeria). African Journal of Biotechnology, Vol. 7(12):(pp.62-171).

6. Bliatti, M,T. and Latif, M. (2011). Assessment of Water Quality of a River using an Indexing Approach during the Low-flow Season Irrigation Drainage, Journal of Agriculture and Environment, (60): (103-114).

7. Chapman, P.M. and Ronberg, G.P. (2008). Design of Monitoring Studies for Priority Pollutant. Journal of industrial Waste, 56(5):(pp.200-204).

8. Jeje, C. Y. and Fernando, C. H. (1986). A Practical Guide to the Identification of Zooplankton in Nigeria (Cladocera, Copepoda and Rotifera). KainjiLake Research institute, New Bussa, Nigeria.

9. Kolo, B.G., Ogugbuaja, V.O and Dauda, M. (2010). A Study on the level of suphates, Phosphates, and Nitrates in Water and Aqueous Sediments of lake chad basin area of Borno State, Nigeria. Continental Journal of Water, Air and Soil Pollution, 1: (pp.13-18).

10. Locke, A., Sprules, W.G., (1994). Effects of lake acidification and recovery oil the stability of zooplankton food webs. Ecology 75, (pp.498506).

11. Moss, B. (2007). Shallow lakes, the water framework directive and life. What should it all be about? Hydrobiologia 584, (pp.381-394).

12. Ogbeibu, A.E, and Victor, R. (1989). The effects of road and bridge construction on the bank-root macrobenthic invertebrates of a 
International Journal of Engineering Applied Sciences and Technology, 2020

Vol. 4, Issue 10, ISSN No. 2455-2143, Pages 328-336

Published Online February 2020 in IJEAST (http://www.ijeast.com)

southern Nigeria stream. Environmental pollution, Vol.56, Issue 2, (pp.85-100).

13. Ogbeibu, A.E., lmobe, T.O.T., and Edokpayi, C. A. (2001). Zooplankton of a temporary pond in a threatened Nigerian forest reserve: The crustacean tropical freshwater biology.

14. Ogbeibu, A.E. and Obanor D.O. (2002). Studies on the crustacean zooplankton of in impounded river in southern Nigeria Bioscience research 14(6): (pp.579-587).

15. Ogbeibu, A.R, and Victor, R. (1989). The effects of road and bridge construction on the bank root macroinvertebrates of a southern Nigeria stream. Environmental pollution,56: (pp.85-100).
16. Onyedineke, N.E., Nwigwe, I.C. and Emeronye, R.U. (2009). Physical and Chemical Hydrology of Abadaba Lake, Imo State, Nigeria. Advances in Science and Technology Vol.3: (pp.183-193).

17. Ude, E.F., Ugwu, L.L..C., Mgbenka, 11.0. and Nwani, C.D (2011). Trends in Nitrate-Nitrogen, Nitrite-Nitrogen and Phosphorus Concentration in Ebonyi River, Nigeria. Continental.

18. Robinson, A. H.and Robinson, I. K.( 1971). Seasonal distribution of zooplankton in the Northern basin of Lake Chad. Journal of Zoology, 163: (pp. 25-61).

19. Zeb, B.S, Malik A.H, Awaseem and Mahmood Q, (2011). Water Quality Assessment of Siran River, Pakistan. International Journal of Physical Science, (6): (pp.789-798) 